\title{
Luis Enrique Osorio (1915-1930): itinerancia juvenil y transferencias culturales*
}

Fecha de recepción: 24 de agosto de 2021

Fecha de aprobación: 19 de octubre de 2021

\section{Resumen}

Este artículo revisa la trayectoria de Luis Enrique Osorio entre 1915, año de publicación de su primera obra, y 1930, cuando cierra su ciclo como editor del proyecto $L a$ Novela Semanal, con el fin de estudiar sus posturas como autor y editor. La teoría de las transferencias culturales (Espagne; Zapata) y la categoría de postura autorial (Meizoz) permiten comprender las estrategias a las que acudió Osorio para construir una postura de autor y editor, y para tratar de vincularse a la dinámica cultural colombiana de la primera mitad del siglo xx. El análisis permite confirmar que la trashumancia de juventud, su relación con impresos periódicos colombianos y extranjeros, y sus relaciones con escritores, editores e intelectuales latinoamericanos son determinantes en la carrera de Osorio en los circuitos editorial, literario y teatral; no obstante, le resultan insuficientes para consolidar la postura autorial y de editor que anhelaba.

Palabras clave: edición colombiana, literatura colombiana siglo xx, Luis Enrique Osorio, transferencias culturales.

Citar: Agudelo Ochoa, Ana María. "Luis Enrique Osorio (1915-1930): itinerancia juvenil y transferencias culturales". La Palabra, núm. 41, 2021, e13320. (iㅏ https://doi.org/10.19053/01218530.n41.2021.13320

\section{Ana María Agudelo Ochoa}

Doctora en Filología por la Universidad de Barcelona, magíster en Literatura Colombiana de la Universidad de Antioquia. Profesora titular de esta última universidad. amaria.agudelo@udea.edu.co (D) https://orcid.org/0000-0002$\underline{5406-3133}$

* Artículo de investigación. Este artículo de investigación se deriva del proyecto de investigación "Digitization and Analysis of Cultural Transfers in Colombian Literary Magazines (1892-1950)" financiado en la convocatoria Universidad de Antioquia (UdeA-DFG); se inscribe, además, en la Estrategia de Sostenibilidad para los grupos de investigación convocatoria 2019 de la misma universidad. 


\section{Luis Enrique Osorio (1915-1930): Cultural Transfer and his Juvenile} Mobility

The time frame of this research is between 1915, when Luis Enrique Osorio published his first work, and 1930 when he finished La novela semanal [Weekly Novel] as its editor. That is why this paper studies Osorio's points of view as an author, but also as an editor during this period. The theory of the cultural transfer by Michel Espagne and Juan Zapata -and the concept of "staging by the author" coined by Jérôme Meizoz are applied here to recognize the ways Osorio considered to build his position as an author and as an editor in Colombia. This study contributes also to appreciate Osorio's insertion in the Colombian cultural stage in the first half of the XX century. The result shows up the failure by Osorio to set a right position up as a prestigious author and editor as he wanted -no matter his juvenile cultural network mobility, his participation in national an foreign recognized cultural printed journals, and his relationship with important Latin-American authors-editors-and scholars.

Keywords: Colombian Edition, Colombian Literature XX Century, Luis Enrique Osorio, Cultural Tranfer.

\section{Luis Enrique Osorio (1915-1930): itinerância juvenil e transferências culturais}

\section{Resumo}

Este artigo revisa o percurso de Luis Enrique Osorio entre 1915, ano de publicação da sua primeira obra, e 1930, data na que fecha o seu ciclo como editor do projeto O Romance Semanal, com o objetivo de estudar os seus posicionamentos como autor e editor. A teoria das transferências culturais (Espagne; Zapata) e a categoria de posição autoral (Meizoz) permitem compreender as estratégias utilizadas por Osorio para construir um posicionamento de autor e editor, e para tentar vincular-se à dinâmica cultural colombiana da primeira metade do século XX. A análise possibilita confirmar que a sua transumância de juventude, a sua relação com jornais imprimidos, tanto colombianos quanto estrangeiros, e a sua proximidade com escritores, editores e intelectuais latino-americanos foram determinantes na carreira de Osorio nos circuitos editorial, literário e teatral; no entanto, resultaram-lhe insuficientes para consolidar a posição editorial e de autor que ele desejava.

Palavras-chave: edição colombiana, literatura colombiana século XX, Luis Enrique Osorio, transferências culturais. 


\section{Introducción}

Luis Enrique Osorio (Bogotá 1896 - 1966) incursionó a lo largo de su vida en el teatro, como autor y director; en el periodismo, como reportero y editor; en la literatura, como escritor y editor; y en la política, más como un idealista que como una persona vinculada a cargos estatales. Pese a que él apostó a la popularización de la literatura, o tal vez por ello mismo, Osorio es una figura prácticamente desconocida por parte de la historiografía literaria colombiana. Este estudio analiza, desde la perspectiva de las transferencias culturales, los inicios de la trayectoria de Luis Osorio como escritor, periodista y editor; específicamente en el periodo que va desde 1915, año de publicación de su primera obra, Primer amor. Novela de actualidad, hasta 1930, cuando cierra su ciclo como editor del proyecto La Novela Semanal. Los viajes fuera del país durante su juventud, sus colaboraciones en periódicos y revistas colombianas y extranjeras, y sus relaciones con escritores, editores e intelectuales latinoamericanos de su época, resultan fundamentales en la construcción de sus posturas como autor y editor. Se entiende el concepto de "postura" en los términos de Jérôme Meizoz, quien la define como "la manera singular de ocupar una posición en el campo literario" (12), "una manera de enfrentarse, como se dice comúnmente, o de adoptar una figura (buena o mala) a partir de las ventajas y desventajas provistas por la posición que se ocupa en el juego literario" (14).Como clave metodológica, este autor señala que no basta con describir los elementos más visibles de una postura: es necesario ubicarla en el entramado de relaciones del sistema literario (14). Así, además de presentar los elementos característicos de la postura asumida por Osorio, se revisará la red de vínculos en los que se inserta, tanto en Colombia como en los países que visita. La pregunta por las motivaciones y significaciones de las transferencias permitirán describir y comprender las estrategias a las que acudió Osorio para construir una postura de autor y editor, pues no es suficiente con

constatar la presencia de un objeto, de un comportamiento, de un concepto, etc., en dos o más espacios separados por fronteras temporales, lingüísticas, geográficas o culturales. Es preciso que el objeto de la transferencia circule, se ponga en escena y se inserte en redes que disponen ya de una estructura institucional. (Zapata)

Para lograr el objetivo de este artículo, se intentará reconstruir la trayectoria del autor siguiendo un orden cronológico, que permita detectar sus pasos en la acumulación de capital simbólico y de relaciones sociales e intelectuales.

\section{Los inicios}

¡Qué gratas eran aquellas veladas en que nuestros maestros se quitaban la sotana para interpretar con sus alumnos unos dramones para hombres solos... solos en cuanto a los personajes de la obra; porque el público sí era mixto y nutridísimo. "Mi vida teatral".

-El Heraldo (Barranquilla, 30 de octubre de 1951).

Luis Enrique Osorio nace a finales del siglo XIX en Bogotá, en el seno de una familia conservadora. El compromiso de su abuelo con este partido político deriva en la desbandada 
de varios de sus tíos paternos, todos liberales, hacia Venezuela (Barrero 38). La niñez y la juventud de Osorio transcurren en un país en donde se respira un aire conservador producto del régimen que se instaló con Rafael Núñez, en la década de 1880, y que solo comenzaría a superarse en el decenio de 1930. El interés por las artes escénicas caracterizó a su familia (Museartes), a este influjo se sumó el de la escuela: los primeros años de educación de Osorio estuvieron a cargo de jesuitas y de salesianos, de estos últimos, recuerda las veladas de interpretación teatral: “iQué gratas eran aquellas veladas en que nuestros maestros se quitaban la sotana para interpretar con sus alumnos unos dramones para hombres solos... solos en cuanto a los personajes de la obra; porque el público sí era mixto y nutridísimo" (citado en Barrero 41). Luego, pasó al Colegio del doctor Manuel Antonio Botero y terminó su bachillerato en el Colegio Mayor de Nuestra Señora del Rosario (Barrero 41).

A la edad de 17 años, cuando aún cursaba estudios de bachillerato, escribe Primer amor. Novela de actualidad, la cual sería su primera obra publicada en formato libro en 1915. En la dedicatoria, a Rafael María Carrasquilla, explica las peripecias para lograr la impresión y se excusa por algunas faltas de estilo: "es un ensayo estudiantil que, escrito a la edad de diez y siete años, durante mi internado de 1913, me trajo el capricho de la publicidad" (Osorio s.p.). Se trata de una edición a cargo del autor y que tuvo que pasar por dos imprentas para poder llegar a buen final.

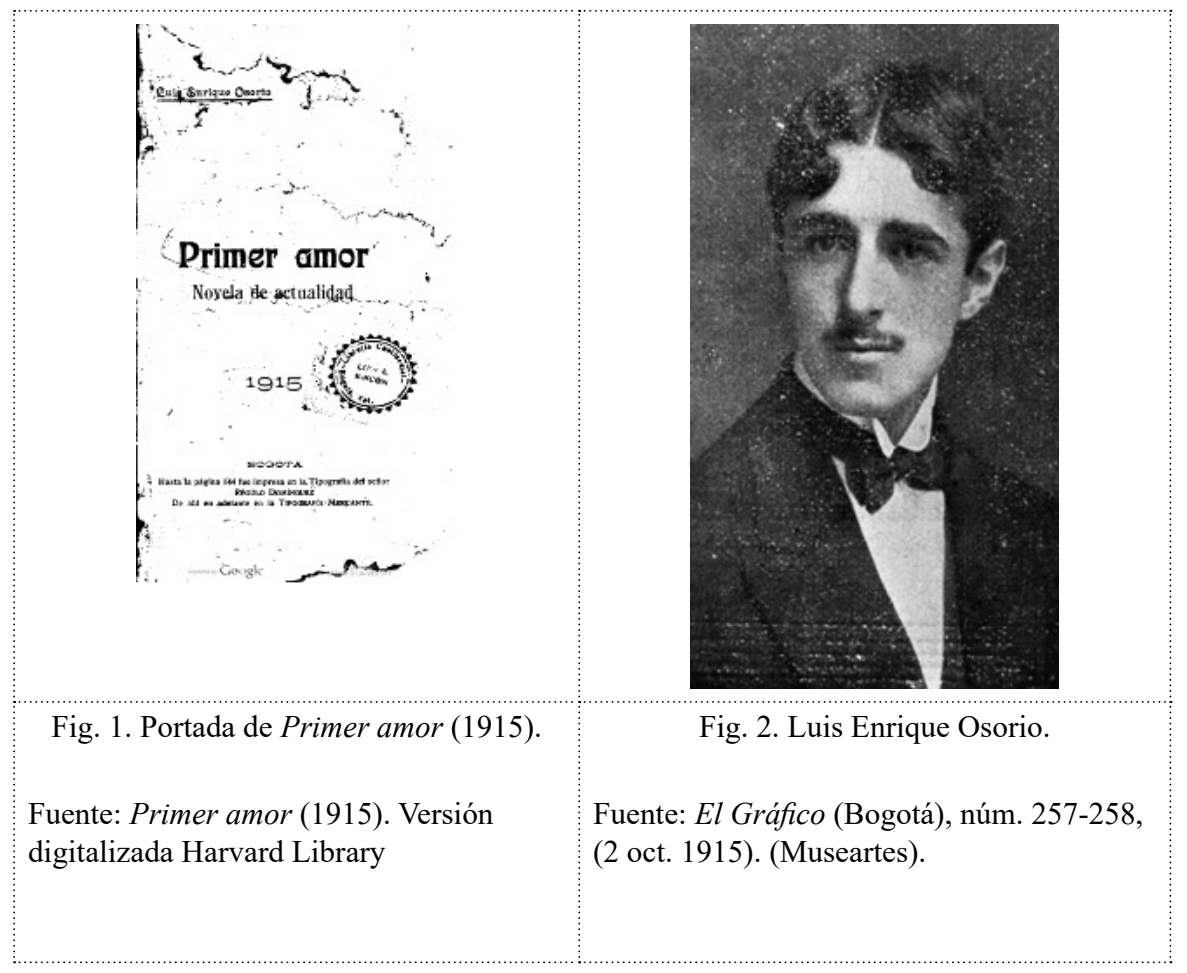


Osorio inició estudios de ingeniería civil, luego optó por el derecho; sin embargo, no terminó ninguna de las dos carreras. Pese a ello, las aulas universitarias animaron su espíritu artístico, allí coincidió con figuras como Antonio Álvarez Lleras (Museartes). ${ }^{1}$

Además de explorar la novela y demostrar interés ya desde niño por la dramaturgia, el joven Osorio incursiona en el periodismo. Giraldo Gallo lo ubica como redactor del Diario Nacional en 1916 con los artículos: "Visita al tenor Eugenio de Folco" y "El Lazareto de Contratación". En 1917, el autor publica su segunda novela, Lo que brilla, con la Imprenta y Litografía de Juan Casís y, un año después, en la misma imprenta, publica Flor tardía. Drama en tres actos y en prosa, obra que había sido llevada a escena en 1917. En 1918 es víctima de la censura, las presentaciones de su obra La ciudad alegre y coreográfica deben ser suspendidas debido a la molestia que el tono crítico despierta entre cierto sector de la clase dirigente (Museartes). Durante su niñez y su juventud, el influjo familiar y escolar hacen aflorar en Luis Enrique Osorio un interés en la escritura y en el teatro. Asimismo, le surge el interés por figurar en la escena pública, no es gratuito que en el texto a Carrasquilla admita que cede al "capricho de la publicidad". Puede interpretarse su fracaso universitario como un intento de adaptarse a las convenciones que imponen, al mejor estilo decimonónico, una doble faceta del escritor: el ejercicio de una profesión respetable y el cultivo de la literatura como una opción secundaria. No obstante, cuando Osorio intenta poner en primer lugar su faceta crítica, a través del arte, es víctima del ambiente conservador y ello lo lleva a autoexiliarse, a emprender un periplo que le permitiría acumular un capital simbólico y una red de relaciones que marcarían profundamente su trayectoria. La imagen de autor que pretende construir, en ese entonces, no encaja en el entramado literario bogotano, aún fuertemente determinado por el campo político.

\section{Circuito Caracas, Nueva York, México}

La ingeniosa malevolencia parroquial atribuía las novelas y dramas del adolescente a la pluma de don Lorenzo Marroquín, su pariente cercano, sin advertir el elogio que tal suposición envolvía. Osorio resolvió embarcarse Magdalena abajo y echarse al mundo entre el bolsillo, hostigado de las mezquindades conciudadanas.

-Humberto Tejera, El Heraldo de México.

Decepcionado del ambiente pacato de su ciudad natal, Osorio decide viajar a Venezuela tras una compañía de teatro española, a la que finalmente alcanza en Puerto Rico, con el deseo de que pusiera en escena su obra La Rasposa. Finalmente, logra que la compañía de Manolo Puértolas estrene en Venezuela otra de sus comedias: La Sombra (Samper 8). El circuito venezolano es posible gracias al apoyo de uno de sus tíos, posiblemente alguno de los que viajaron huyendo del conservadurismo familiar. Este último ambiente, en suma, con la escena escolar y los vínculos laborales y sociales capitalinos constituyen una primera etapa

Álvarez, pocos años menor que Osorio, despuntó en la escena teatral con la obra Víboras sociales en 1911. Ambos son reconocidos por la historiografía del teatro colombiano como los principales dramaturgos de la primera mitad del siglo XX (Prada). 
en la formación intelectual y artística de Osorio. No obstante, no hereda ni acumula durante ese periodo el capital intelectual ni social que le permitan legitimarse en Bogotá.

En 1919, el joven Osorio se radica en Nueva York, ciudad donde, aparte de ejercer oficios que le permitieran subsistir, continúa cultivando el periodismo, la narrativa y el teatro. En esta ciudad publica Sueños fugaces y escribe, para el teatro, Al amor de los escombros, obra que su amigo, el profesor Max Emmanuel Kahn, traduce al inglés bajo el título de Out of the ruins (The Pantagraph 5). Desde Nueva York envía colaboraciones a periódicos como el español Literatura Hispano-Americana. Suplemento Ilustrado, en el cual aparece su poema "Es un anhelo el mío...", en 1919; y en la publicación costarricense Repertorio Americano, donde aparece la reseña "Roberto Brenés Mesén. Dos palabras sobre su obra poética", en 1920. El periodista mexicano Humberto Tejera reconoció en ese entonces que la experiencia neoyorquina marcó un punto de inflexión en la trayectoria de Osorio, le aportó la perspectiva del cosmopolitismo:

[...] el espíritu fluctuante y anheloso del joven escritor colombiano, ha encontrado los jugos vitales de las ideas modernas, y se ha saturado de ellos [...] Esta renovación espiritual puede advertirse fácilmente en sus obras recientes, tanto dramáticas, como en los poemas y cuentos o novelas cortas que hemos leído en Pictorial Review, la consagrada revista, en la que actuó como redactor durante algún tiempo. (Tejera 4)

Es pertinente detenerse en Pictorial Review, revista dirigida al público femenino editada en Nueva York, entre 1899 y 1933, y que circulaba mensualmente a lo largo y ancho de los Estados Unidos. Las publicaciones como Pictorial, conocidas como slicks, ${ }^{2}$ aunque apostaban por la circulación masiva, proponían un ideal de lectora de élite, caracterizada por el buen gusto y la distinción; el ideal de estas publicaciones, por cierto, estaba fuertemente determinado por las exigencias de las marcas que publicitaban sus productos en este tipo de revistas (Gruber 350). Pictorial Review se vanagloriaba de su altísimo tiraje, 1.800 .000 ejemplares mensuales, dirigidos a un modelo de mujer "progresista y despierta ama de casa" (New-YorkTtribune 20). ${ }^{3}$

2 Nombre dado a ciertas publicaciones impresas en papel slick, también conocido como papel cuché. Tal denominación se refiere a la mejor calidad de estas revistas, a diferencia de las pulp, publicaciones impresas en papel de baja calidad y, por ende, más baratas.

3 Entre los tópicos abordados por la revista se cuentan madresolterismo, divorcio, economía doméstica, administración del hogar y moda femenina. 


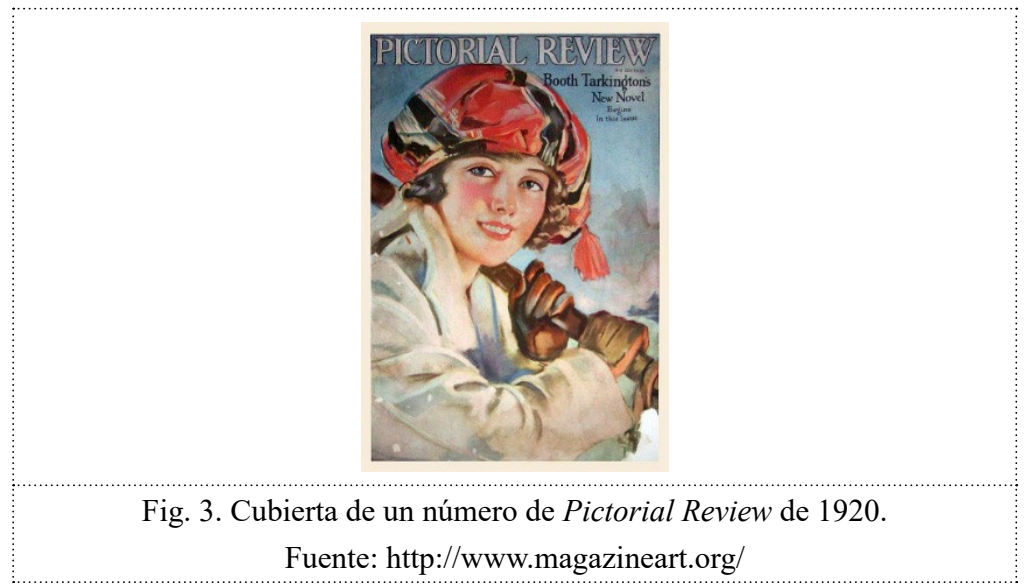

Magazines como Pictorial desempeñaron un papel clave en la divulgación de narrativa breve en Norteamérica y en la formación, libre de paternalismos, de un público lector femenino, lo que se trasluce en uno de sus avisos publicitarios:

Years ago, all women's magazines were blandly offering theire readers mere "stories" as a complement to the more helpful households and needlework pages. Pictorial Review boldly stepped out of the ranks. It was the first to print a novel not written down to a supposedly inmature public. A novel stripped of sentimentality. (“Evening public ledger”)

Osorio trabajó para la versión en español de esta revista: Pictorial Review. Spanish Edition, la cual contaba con agencias en "los veinte países de habla castellana" y oficinas en Nueva York, Berlín, Viena, Madrid, Londres, París y La Habana. Además, compartía algunas características de la publicación principal, se interesaba especialmente por el cuento y la poesía, y le abría espacio a escritores y escritoras del ámbito hispanoamericano.

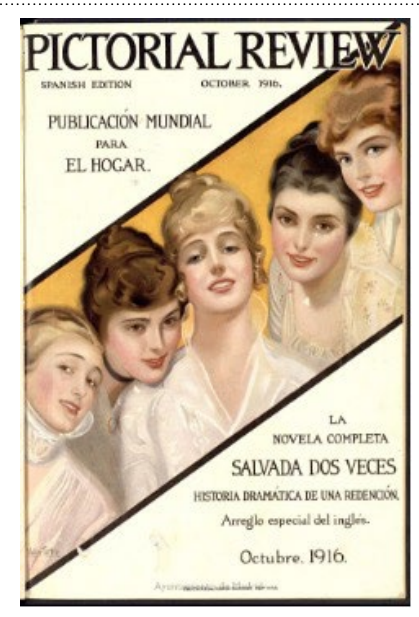

Fig. 4. Cubierta de Pictorial Review Spanish Versión, octubre de 1916.

Fuente: Biblioteca Digital Memoria de Madrid 
La experiencia neoyorkina le permitió a Osorio acumular capital simbólico favorable a su imagen como autor, asimismo, para comenzar a configurar una red de relaciones sociales entre escritores, periodistas e intelectuales extranjeros y materializar su propuesta escrituraria y teatral en medios extranjeros. Impresos como Pictorial, con su contenido - cuentos, novelas cortas y novelas por entregas - y con su materialidad - formato slick - posiblemente estimularon el deseo creativo y empresarial de Osorio. Las características de la revista y de la producción literaria que allí se divulgaba pueden considerarse el primer contacto de Osorio con una publicación periódica de circulación masiva. ${ }^{4}$

Notas en prensa ubican a Osorio en México a finales de 1920. En el artículo "Osorio el joven dramaturgo colombiano", publicado en El Heraldo de México (24 de octubre de 1920), Humberto Tejera le dedica cinco columnas al colombiano y a su obra, reseña la trayectoria del autor, quien para ese entonces rondaba los 24 años de edad, e informa que Al amor de los escombros será llevada a escena por la compañía de Julio Taboada en el teatro El Ideal. La nota está acompañada de un fragmento de la obra. En su entrega del lunes 25 de octubre de 1920, este mismo periódico reseña que en la rectoría de la Universidad Nacional Autónoma tuvo lugar la lectura de la obra en presencia del rector de la institución, de directores de facultades y del cónsul de Colombia. Meses más tarde, el Bulletin of The Panamerican Union (vol. LXII, ene-jun. 1921), 203) reseña la buena acogida que tuvo la puesta en escena de la misma obra, a la cual asistieron el presidente y el cuerpo diplomático latinoamericano y español. El periplo mexicano pone en contacto a Osorio con José Vasconcelos, para ese entonces rector de la Universidad Nacional Autónoma de México. ${ }^{5}$ Según Yankelevich, en 1921, Osorio es delegado por la UNAM para hacer parte de una comisión que representa la institución en países sudamericanos, cargo por el cual percibe algunos ingresos. La sección en Museartes, dedicada a Luis Enrique Osorio, señala que igualmente se encuentra en México y lo vincula a Vasconcelos: "trabaja como mecanógrafo en un banco y, al mismo tiempo, colabora con artículos en la prensa mexicana y en la de Caracas" (párr. 11), Vasconcelos "le da cartas de presentación y recomendación para la universidad en Buenos Aires, cuando Osorio decide ir a dicha ciudad a dictar conferencias. Como de esto no podía vivir, se vincula como maestro en una escuela primaria" (párr. 11).

La experiencia en Norteamérica amplía los horizontes artísticos y las redes intelectuales de Osorio, quien, además de avanzar en su trayectoria como comediógrafo, entra en contacto con una industria editorial sumamente potente. Muy importante es la productiva relación que Osorio entabla con José Vasconcelos, quien "le tomó afecto [...] y lo remitió por cuenta de su gobierno a Buenos Aires, para que divulgase en las universidades argentinas el movimiento cultural que aquél realizaba en Méjico" (Samper 8).

Lamentablemente, hasta ahora no se ha podido encontrar ejemplares donde hayan sido publicadas las obras de Osorio. La relación con Vasconcelos se mantendría a lo largo del tiempo. El Repertorio Americano los ubica a ambos en París en 1926 (sección "Señas de escritores", 25 ene. 1926, 15). Vasconcelos en sus memorias lo rememora en un episodio sobre masonería, específicamente en el apartado "Neuilly Sur Seine”,del libro El Desastre, publicado en México, en 1968, por la Editorial Jus. 
En palabras de Juan Zapata (2016):

Si aceptamos que una transferencia requiere de un espacio que le atribuya una visibilidad mediática y que la inserte en los debates institucionales de una época, es preciso que dicho espacio pueda ser analizado. En la mayoría de los casos, el espacio de enunciación de la transferencia es capitalizado por el mediador. Es allí en donde éste pone en marcha unas estrategias institucionales y discursivas que le permiten posicionar su figura y legitimar su proyecto de importación o de exportación. (7)

Desde esta perspectiva, se podría afirmar que, mediante su itinerario por Venezuela, Estados Unidos y México, Osorio gestiona una postura y una imagen autoriales en círculos extranjeros y consigue, por medio de su vínculo con Vasconcelos, fortalecer una red social que le daría acceso a la institucionalidad cultural mexicana. De hecho, logra hacer parte de una comisión que representa a este país en Argentina.

\section{Argentina: periodismo literario}

De Colombia nos llega Luis Enrique Osorio. Espíritu de una extraordinaria cultura, ebrio de horizontes geográficos y de visiones a lo indefinido, se ha lanzado por esos mundos, dejando a su paso, como estela de sus trayectos, dramas y artículos, versos y novelas, cuentos y descripciones $[\ldots]$.

-Reseña en El Teatro, Buenos Aires (año III, núm. 63, 1922).

Como delegado de la UNAM, Osorio llega a Argentina en 1921. En Buenos Aires, en calidad de reporter para la revista colombiana Cromos, tiene la oportunidad de entrevistar a Juan José de Soiza Reilly, editor de La Novela Semanal de Argentina, quien lo acerca a una idea de ejercicio periodístico al servicio de la literatura y de su popularización. Al respecto, vale la pena citar una afirmación tomada de la entrevista que Osorio hizo a De Soiza Reilly:

Yo creo en lo que dicen los franceses: que el periodismo es una escalera que lleva a todas partes; pero a condición de salir de ella... Yo, por supuesto, me he dedicado a un ramo especial, que es el periodismo literario, modificación que introduje en la prensa argentina en mil novecientos cuatro. (19)

Además de esta entrevista, Osorio publica otras notas en medios colombianos como las revistas Cromos y El Gráfico. En Nueva York había incursionado en el cuento y en la novela breve en clave de popularización de la literatura, en esta misma clave, publica en 1922 en la revista colombiana Cromos — publicación al estilo de los magazines franceses - los relatos: "Por qué la mató", "Por ambos hemisferios", "La carta perfumada", "El lenguaje de unos ojos verdes" y "El pobre autor", relato que también circula en el afamado magazín argentino Caras y Caretas (núm. 1243, 29 jul. 1922). A la par, divulgaba sus relatos en un tipo de publicación periódica que había comenzado a gozar de gran éxito en Argentina, a inicios del siglo, y que se adscribe al conocido "género semanal", del cual era fecundo editor De Soiza Reilly. Ana María Agudelo y Cristina Gil así definen este tipo de publicaciones: 
Con este rótulo, que alude explícitamente a la periodicidad, se suele denominar a algunas colecciones de textos literarios breves, publicados en formato de impreso periódico de bajo costo, muy populares en España y en algunos países de Latinoamérica durante las primeras décadas del siglo XX. (190)

Con una factura similar a las del pulp-fiction norteamericano, las primeras manifestaciones del género semanal las encontramos en España por iniciativa de Eduardo Zamacois, quien en enero de 1907 pone en circulación el primer número de El Cuento Semanal y un par de años más tarde, cuando le es arrebatada la dirección de la publicación, funda Los Contemporáneos (Cordero Gómez; Sánchez García). ${ }^{6}$ El éxito alcanzado en España por El Cuento Semanal, y otras colecciones similares, responde, entre otras razones, al incremento de una clase media consumidora de impresos periódicos, al aumento de población en los centros urbanos y al del público lector en sectores populares (Martínez Arnaldos 15-16).

Margarita Pierini, estudiosa del caso argentino, se refiere al género semanal como un "fenómeno editorial masivo" sin antecedentes en ese país, que se concreta en torno a programas que se venían trazando para la literatura argentina: "apoyo a la literatura nacional", "profesionalización del escritor" y "difusión de la lectura como herramienta de progreso individual y social". En efecto, las diferentes colecciones que circulan preparan "el terreno para una empresa inédita en la Argentina: vincular el interés del lector popular, atraído sobre todo por textos de ficción, con la producción novelística de autores nacionales que reflejen la realidad cotidiana" (en línea). En cuanto a la producción editorial Denise Nagy afirma que:

Entre 1917-1951, las sucesivas fundaciones y disoluciones de las editoriales aplicadas a la comercialización de novelas semanales - y de teatro semanal—indican las transformaciones de las prácticas de lecturas de los sectores urbanos y las variantes en la modalidad de la producción literaria de una comunidad de autores - y de intelectuales - que se vinculó a un proyecto pensado - más allá de los objetivos antes señalados— como una herramienta de intervención social.

La propuesta de Nagy pone el foco en los vínculos editoriales entre la narrativa y el teatro, ambos eran puestos en circulación en el mismo soporte, géneros que, asimismo, concentran la atención de Osorio y resultan convenientes a su futura apuesta editorial a favor de la popularización del teatro y de la literatura.

El primer contacto de Osorio con el género semanal se da en calidad de autor, los antecedentes de esta "fórmula" seguramente los exploró en Nueva York, pero el afianzamiento ocurre en Argentina en donde fue colaborador en varias publicaciones de este tipo con títulos como: "Al amor de los escombros" (Buenos Aires, El Teatro, año 2, núm. 63, 1922), "La bendición" (Novela de la juventud, año III, núm. 71, 1922), "Un romance de viaje” (Novela de la juventud, año III, núm. 87, 1922), "El cementerio de los vivos" (Novela semanal, año 6, núm. 252, 1922 y La novela del día, núm. 241, 1922), "La mujer blanca. Novela mexicana"

6 Belén Puente sintetiza las posturas de varios historiadores de las letras españolas y revisa los posibles antecedentes y modelos de El Cuento Semanal, entre los que se cuentan colecciones francesas como: Lisez-moi, Les Romans de L'Illustration, La Petite Illustration. 
(La novela universitaria, año 2, núm. 42, 1922) y "Malos ojos. Novela caraqueña inédita" (La novela argentina, año1, núm. 41, 1922).

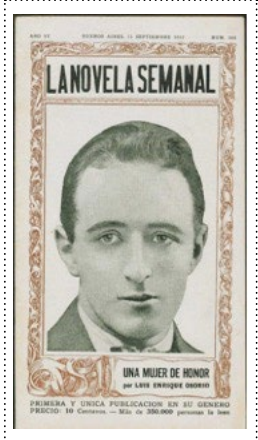

Fig. 5. Cubierta de La Novela Semanal, año IV, núm. 262, Buenos Aires, 11 de septiembre de 1922. En la foto de la cubierta, Luis Enrique Osorio.

Fuente: Instituto Iberoamericano de Berlín.

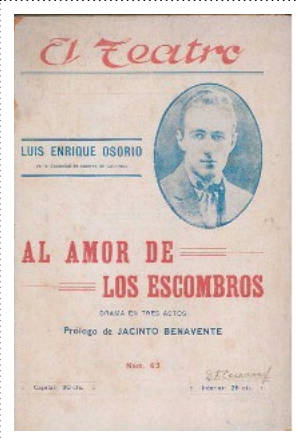

Fig. 6. Cubierta de $E l$ Teatro, año II, núm. 63, Buenos Aires, 12 de junio de 1922. En la foto de la cubierta, Luis Enrique Osorio.

Fuente: Instituto Iberoamericano de Berlín.

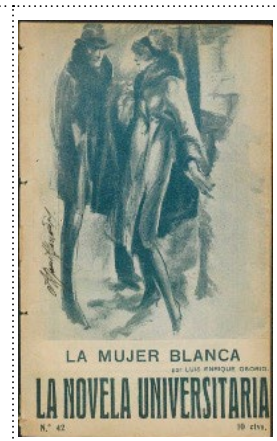

Fig. 7. Cubierta de La Novela Universitaria, año II, núm. 42, Buenos Aires, 21 de junio de 1922.

Fuente: Instituto Iberoamericano de Berlín.

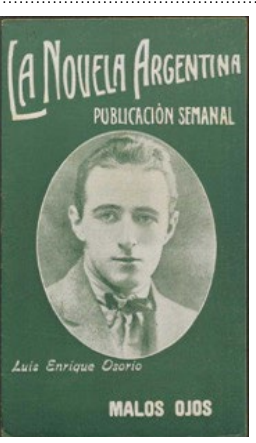

Fig. 8. Cubierta de La Novela Argentina. año 1, núm. 41,

Buenos Aires, 15 agosto de 1922. En la foto de la cubierta, Luis Enrique Osorio.

Fuente: Instituto Iberoamericano de Berlín.

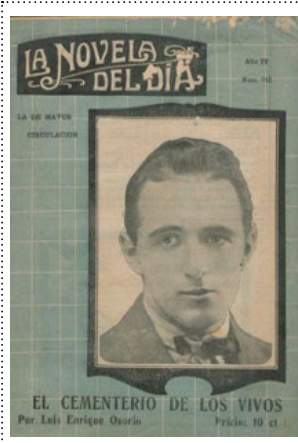

Fig. 9. Cubierta de $L a$ Novela del Día, año 4, núm. 241, Buenos Aires, 25 de agosto de 1922. En la foto de la cubierta, Luis Enrique Osorio.

Fuente: Instituto Iberoamericano de Berlín

La reseña bibliográfica publicada en La Novela Universitaria presenta un listado de las obras de Osorio. Aparte de las antes citadas, esta reseña menciona la publicación de "Lo que agradece una mujer" (La Novela Nacional), "La tragedia de Broadway" (La Novela del Día), "Una mujer de honor" (La Novela Semanal, Argentina), "Sueños fugaces" (La Juventud), "Los desterrados" (La Novela del día), "Venganza del amor" (sin dato) y el libro de poesía Frutos de mis andanzas (editado por Repertorio Americano, prologado por Smitri Ivanovitch). Llama la atención que no se mencione su labor en Pictorial Review.

La estancia en Argentina se ve interrumpida, pues la muerte del padre obliga a Osorio a viajar a Colombia; no obstante, regresa al Sur del continente. Al parecer, mientras estuvo en Bogotá, publicó y llevó a escena Sed de justicia: alta comedia en tres actos y en prosa (Bogotá, Cromos), y llevó a escena Al amor de los escombros y La culpable (Museartes).

\section{Regreso a Colombia: de autor a editor}

Traje al suelo nativo, si no los millones de Arlequín, al menos un pequeño fardo de experiencias. Entre ellas venía la idea, captada en Argentina, de publicar con temas de la tierra una 
Cuando regresa a Colombia, en 1922, la prensa continúa operando como el principal circuito de divulgación de la literatura y de formación de público lector en el país. La industria editorial nacional está en ciernes, no existe un circuito afianzado del libro, mucho menos un amplio público lector. Los roles del editor y el impresor aún se confunden. ${ }^{7}$ La narrativa breve circula principalmente en periódicos y revistas. Pese a las condiciones precarias, Osorio funda su empresa editorial: "a orillas del río San Francisco, en un oscuro sótano, imprime la revista Novela Semanal. En esta publica a escritores colombianos y novelas suyas" (Museartes párr. 13). Para ese entonces, es un comediógrafo activo, ha ejercido como reporter para medios nacionales y extranjeros, ha establecido una amplia red de contactos y, además, ha entrado en contacto con empresarios culturales argentinos convencidos del éxito de los vínculos entre el periodismo y la literatura. Sus intereses creativos habían empezado a emerger cuando aún residía en Colombia, pero es gracias al periplo americano que acumula ideas y bríos, que sienta las bases para que asumiera una postura de autor/editor, de empresario cultural, a la manera de Eduardo Zamacois, en España, o de Juan José de Soiza Reilly, en Argentina.

Se puede afirmar en este punto que Osorio es el importador del "género semanal" a Colombia y con ello configura un hito en la aparición del editor moderno en el país. Entre enero de 1923 y noviembre de 1924 circulan las revistas La Pluma Semanal, El Cuento Semanal y La Novela Semanal, cuya materialidad es muy similar a las homólogas argentinas en las que colaboró Osorio, asimismo su política editorial. La Novela Semanal, publicación principal, se concentra en la obra de autores colombianos; El Cuento Semanal en autores extranjeros; mientras que La Pluma Semanal acude al contenido misceláneo. Inicialmente, Editorial Colombia es la encargada de la impresión de los ejemplares, luego pasa a serlo Talleres Tipográficos de la Novela Semanal, finalmente, la editorial Nuevo Mundo. Osorio se reconoce a sí mismo como autor/empresario, de hecho, figura como Editor Propietario en las portadas de El Cuento Semanal y declara la intención de promover la producción, divulgación y lectura de una literatura nacional, así como el renacimiento de la "fe en la vida patria", a partir de "la creación de un nuevo género literario": la "novela corta" (La Novela Semanal, núm. 78, 406; núm. 101, s.p.). Su política editorial va en la misma vía de los medios argentinos en los cuales colaboró.

La Novela Semanal comienza a circular el 25 de enero de 1923. Por otro lado, con un tiraje de 5000 ejemplares, El Cuento Semanal comienza a circular el sábado 19 de mayo de 1923 - "La novela extranjera" es su subtítulo- . La primera etapa de esta publicación alcanza 23 números, la segunda etapa comienza a circular el 17 de noviembre de 1923 y deja de aparecer el 18 de diciembre de 1923. Durante toda la vida de la publicación, el valor de cada ejemplar es de 5 centavos. Por su parte, La Pluma Semanal empieza a circular el 22 de mayo de 1923. El Cuento y La Pluma alcanzan pocos números, 23 y 2 respectivamente, mientras que La Novela Semanal logra en su primer momento más de 100 entregas. En la narración autobiográfica titulada "Odisea de un autor en busca de público", Osorio relata:

Sobre el estado del campo editorial colombiano de principios del siglo XX puede consultar: Marín Colorado "Las empresas editoriales...", "La colección Biblioteca popular...", Un momento en la historia...; Pineda Cupa "Jorge Roa y la Librería Nueva..."; Agudelo, Marín y Guzmán La edición de cuento en Colombia... 
A crédito lancé esa pequeña revista, que aunque mal impresa animó muchas vocaciones y anduvo todos los caminos de Colombia. Aun se cruzaban en mula el Quindío y el Almorzadero pero el folleto fue a las más escondidas aldeas llevando, junto con mi repertorio de chico trashumante, los primeros ensayos de Daniel Samper Ortega, Manuel García Herreros, Gregorio Castañeda Aragón, Antonio J. Lemos Guzmán, Bernardo Arias Trujillo, Simón Latino, Luz Stella, y otros muchos escritores que más tarde llegaron a manejar academias y universidades [...]. (s.p.)

Luis Enrique Osorio se propone ofrecer una plataforma que haga las veces de escuela para nuevos autores, apueste por una amplia difusión y masificación de la cultura; para esto conjuga en su postura autorial al narrador y comediógrafo con el empresario editorial que encuentra en los altos tirajes de la prensa un medio para cumplir sus objetivos:

Para reforzar nuestro optimismo basta comparar las iniciaciones de los escritores argentinos con la producción que hoy están publicando, después de cuatro años de práctica [...] Los noveles tienen ya una escuela que, si no es la impecable de una selección genial, lleva en sí toda la fuerza de una tendencia nacionalista que va contra el parasitismo fatal a que siempre hemos venido subordinándonos. (La Novela Semanal, tercera serie, núm. 53, ene. 1924) ${ }^{8}$

Él mismo hace uso de su proyecto como plataforma de divulgación de su narrativa: en La Novela Semanal publica 15 relatos en menos de dos años: "La mujer blanca", "Sueños fugaces", "Malos ojos", "Los que jugaban al amor", "La tragedia de Broadway", "La mágica ciudad del cine", "El cementerio de los vivos", "El beso del muerto", "Una mujer de honor", "Paso a la reina", "Lo que agradece una mujer", "La culpable", "Si, mi sol", "La bendición" y "La Torre".

Cabe recordar que Osorio había entrado en contacto con el modelo slick - con su materialidad y diseño cuidados-, propuesta editorial opuesta a la de otro género editorial, también de moda en Estados Unidos, en ese entonces: los pulp-fictions, editados en papel barato, con altos tirajes y cuya línea editorial no tenía resistencia frente a temas sensacionalistas. La materialidad de La Novela Semanal argentina es cercana a la de las publicaciones pulp. Tanto la propuesta del slick como la del pulp-fiction se traslucen en el modelo de negocio editorial al que le apuesta Osorio a su regreso a Bogotá. Según Zapata, el soporte de la transferencia cultural ofrece elementos para comprender el nuevo sentido del que se carga la idea, el objeto cultural o la pose autorial transferidos (8). En este caso, la materialidad de La Novela Semanal, editada por el colombiano, revela elementos tanto de sus homólogas argentinas como de los slicks norteamericanos. La materialidad se acerca a la de estos últimos. La política editorial interesada por la ficción corta y por la divulgación de nuevos autores puede provenir de ambos modelos. El cuidado en la selección de contenidos alejados del sensacionalismo y el interés por circular entre el público lector femenino es propio del slick. Osorio se atrevió a abrirle un espacio al género galante en El Cuento Semanal, pero este no fue bien recibido.

Debido a las reacciones adversas, Osorio opta por cambiar el enfoque de El Cuento Semanal. En sus inicios, esta publicación pretende divulgar obra de autores extranjeros; no

No me detendré en los detalles del proyecto editorial, al respecto véase: Gil Medina "El cuento en La Novela Semanal..."; Agudelo y Gil "Impresos periódicos...". 
obstante, en el número 5 se anuncia que la revista aceptará obras de autores nacionales que por su temática no tengan cabida en La Novela Semanal.

Era nuestro propósito publicar únicamente novelas extranjeras de los más connotados autores del mundo, que sirvieran de modelo a nuestros intelectuales noveles, en este dificilísimo género del arte moderno, sin embargo, hállanse en nuestra mesa de redacción algunas obras nacionales que, a pesar de su mérito artístico, no pueden darse al público en las columnas de LA NOVELA SEMANAL por su argumento un tanto realista, reñido con el carácter familiar de esa publicación. (sección "Ecos de El Cuento Semanal”, El Cuento Semanal, núm. 5, 1923, 78)

Osorio, familiarizado con los lectores neoyorkinos, mexicanos y argentinos, optó por un modelo editorial para este público, no calculó en primera instancia la singularidad del público colombiano y, por ello, se vio obligado a ajustar en algunos puntos su política editorial:

En el ambiente pacato de la ciudad la aparición de La Novela Semanal dio origen al fruncimiento general y colocó un tono de rebeldía, pagano y sincero, al cual no se podían acomodar las reservas acostumbradas de nuestros católicos fervorosos. Este pueblo grande que recibe hipócritamente la afluencia de lecturas pornográficas [...] puso el grito en el cielo por la índole de nuestra revista [...] Seguimos hoy un nuevo rumbo sin arrepentirnos de lo hecho; quizá una ley atávica, herencia de antigua galantería española, oblíganos a respetar el querer de muchas damas, cuyos ojos nos han mirado severos. (“¿Claudicación?”, El Cuento Semanal, núm. 1, 1924, segunda etapa, 15)

Pese a las transformaciones, cierto sector de la élite literaria bogotana al parecer no recibe con mucho agrado el proyecto de Osorio, quien propone una plataforma para autores noveles, un vehículo de popularización de la literatura y un espacio para géneros en ese momento tratados de soslayo. León de Greiff, para ese entonces joven poeta de la misma edad de Osorio, pone en duda la calidad de la apuesta del editor, en una carta a su hermano afirma que: "Muy buena idea me parece la de esa publicación [se refiere a Lectura Breve]. Y que ojalá no sigan las huellas de la Novela Semanal de Osorio, que ha salido con semejantes pendejadas" (De Greiff), 17. En el artículo "Por el arte propio" el novel editor sienta su postura y reacciona frente a las críticas a su proyecto:

Es inútil pretender que las obras que publica LA NOVELA SEMANAL sean todas maestras, aunque procedan de plumas maestras. El género comienza a cultivarse entre nosotros, y no puede nacer absolutamente definido. Valerse de este recurso para pretender que se publiquen novelas extranjeras es manifestar muy poco amor a nuestra personalidad como nación. La literatura propia para que surja debe ser estimulada, y no desalojada. Pretender que el extranjero venga a sustituirnos en toda forma es tener muy triste idea de nosotros mismos. (La Pluma, núm. $1,1923,13)$

Curiosamente, en otras regiones del país Osorio encuentra editores interesados en su labor, prueba de ello es el vínculo entre las publicaciones medellinenses Sábado, Lectura breve y el proyecto editorial de Luis Enrique Osorio. Es de conocimiento que este, al iniciar su empresa, se pone en contacto directo con escritores y editores de diferentes zonas del país, para convocarlos a participar y, tal vez, vincularlos en sus revistas. De esta relación con los 
editores y escritores antioqueños, quedan evidencias en la publicación Sábado. En el artículo "Impresos periódicos y popularización de la literatura en Colombia (1913-1930)", se señalan que en Sábado aparece publicada una carta que Osorio dirige a Federico Villa, en esta misiva "reiterar su interés por ofrecer espacio a escritores comprometidos con la renovación del fondo literario nacional", además "insiste en el objetivo de La Novela Semanal y lanza la convocatoria de un concurso de novela breve". Las autoras del artículo sostienen que, "Osorio es enfático [en esta carta a Federico] al afirmar que la verdadera literatura nacional ha de escribirse en las regiones y al señalar la necesidad de que la literatura llegue a todos los sectores de la sociedad y rincones del país" (203):

El hecho de haber ofrecido al público obras en las cuales se refleja nuestra propia vida, ha sido motivo suficiente para lograr una circulación sin precedentes en Colombia. Puede decirse que la Revista que tengo la honra de dirigir es el órgano que está llevando a los autores nacionales al corazón de las masas, sacándolos del aislamiento anonadador en que antes se encontraban. (“Concurso nacional”, Sábado, núm. 87, 1923, 1051)

Villa, además de brindarle a Osorio un espacio de resonancia en Sábado, dedica un artículo a elogiar el proyecto:

Desde el punto de vista intelectual, la tarea de Luis Enrique Osorio representa un progreso para nuestra patria y un estímulo para los aficionados a escribir, por lo cual esperamos que el consumo sabrá corresponder al enorme trabajo que demanda en nuestro medio incipiente una publicación de este género [...] ahora tendrá el público en "La Novela Semanal", amena y abundante lectura, escogida por un escritor diestro e inteligente, y a un precio módico, hasta [para] las personas más pobres. (“La Novela Semanal”, Sábado, núm. 89, 1923, 1073-1074)

Lectura breve comienza a circular justo tres meses después de que lo hiciera La Novela Semanal; no es gratuito el énfasis en los autores antioqueños. Como señalan Agudelo y Gil, es posible

aventurar incluso que la revista editada en Medellín es una respuesta de apoyo contundente a las ideas de Osorio. De ahí que en Sábado se anuncie Lectura Breve como una "publicación literaria" autónoma, que procura asumir un formato similar al de La Novela Semanal. (204)

A la par de su incursión en el mundo de la edición de capital privado, Osorio avanza en su papel de dramaturgo y director. Su conocimiento y preocupación por el teatro colombiano se traslucen en artículos que publica en sus medios y en otros periódicos impresos. ${ }^{9}$ También en este campo se enfrenta a muchos obstáculos. En una carta abierta al presidente Pedro Nel Ospina, publicada en El Tiempo el 25 de abril de 1924, solicita el apoyo estatal para el desarrollo de sus proyectos culturales, bajo el argumento de que "el arte literario es la base de la personalidad nacional" (9). Al parecer el presidente, de quien Osorio se había declarado opositor, hizo oídos sordos a su solicitud: "todo lo cual le acarrea el retiro de los patrocinios

"Por el arte del teatro colombiano: concurso para premiar la mejor obra", La Novela Semanal, vol. 2, núm. 57 (21 feb. 1924): 96-98. "Teatro colombiano", Revista de la Biblioteca Nacional de Bogotá, vol. 1, núm. 10/11 (may-jun. 1924); "Modelos para nuestro teatro", Cromos, núm. 411, 1924, s.p. 
a la Novela Semanal. Entonces decide vender la imprenta y viajar a Europa" (Museartes párr. 15). Como él mismo lo relata:

El desencanto que me dejaron dos años de lucha para implantar en mi país un movimiento de arte raizal, y la vergonzosa indiferencia de los gobernantes colombianos de esa época ante toda alta manifestación del espíritu, indujéronme a emigrar en busca de ambiente propicio a mis entusiasmos, a penetrar una lengua y espíritu extraños. (citado en Giraldo Gallo 101)

Osorio no logra el reconocimiento que esperaba por parte de la institucionalidad literaria, ni por parte de la política. Su postura autorial, forjada hasta ese entonces en el exterior gracias a la capitalización de vínculos con intelectuales extranjeros, no fue suficiente para hacerse a un lugar en la arena literaria del país. Por otro lado, su apuesta editorial no contó con las condiciones propicias para una apuesta de capital privado, con una política que trasciende las funciones limitadas del impresor, las más comunes en Colombia en esa época. El proyecto de Osorio antecede al de Germán Arciniegas, Ediciones Colombia, estudiado por Paula Marín (Un momento en la historia de la edición...). Como Arciniegas, Osorio apuesta por la literatura, por autores vivos y por la gestión autónoma de recursos. No obstante, las tensiones con la clase dirigente colombiana, que le costaron su primer autoexilio, se mantienen y lo embarcan a un proyecto teatral en París.

\section{Bogotá-París-Barranquilla: ansias de internacionalización}

M. Luis Enrique Osorio, auteur dramatique colombien et journaliste de talent, est arrivé á Paris, chargé, par un important journal de Bogota, de faire une enquête sur le mouvement théâtral en France.

-The New York Herald, 23 de febrero de 1925.

De nuevo la decepción motiva a Osorio a abandonar Colombia, aunque en esta ocasión emprende un viaje más ambicioso que lo lleva a Francia. El periódico Le Gaulois (23 de febrero de 1925,2) anuncia la llegada del joven dramaturgo colombiano como corresponsal de un importante periódico de su país. En París, se concentra en sus diversas facetas: dramaturgo, director de teatro y periodista, y continúa su colaboración con la revista colombiana Cromos ${ }^{10}$ asimismo colabora con La Antorcha, semanario de José Vasconcelos ${ }^{11}$, y con la revista francesa Paris-Sud Amérique, de Louis Forest (Museartes). ${ }^{12}$ La red de contactos que había capitalizado y la trayectoria como periodista resultaban prometedoras para Osorio, cuya postura autorial pretende transformar adoptando una pose afrancesada. Además de tratar de posicionarse como conocedor de la escena teatral del país galo, se aventura a escribir en esa lengua, la cual había adquirido a poco tiempo de llegar a Francia.

10 Entre 1925 y 1926 publica los artículos "Las gaviotas", "El poeta y dramaturgo Paul Géraldy", "Dramaturgo francés Edouard Bourdet" y "Crónicas de París".

Allí publica "Crónicas de París. Herriot y el vaticano" (México, Tomo I, núm. 18, 31 ene. 1925, 25)

12 "Par-Sud-Am. Paris-Sud-Amérique. Journal des Américains latines en France et des Français en Amérique, después llamado Paris-Sud et Centre-Amérique, se publicó entre 1925 y 1938. Fundado por el periodista Louis Forest [...] Además de las noticias sobre los países suramericanos, Par-Sud-Am cubrió regularmente las noticias de América Central y del Caribe, lo cual le dio un alcance que otras publicaciones no tuvieron" (Rojas párr. 56). 
El 16 de octubre de 1926, Osorio imparte la conferencia "Tendencias del teatro francés contemporáneo" en la Residencia de Estudiantes, centro asociado a la Junta para Ampliación de Estudios. ${ }^{13}$ Varios medios madrileños anuncian el acto académico. ${ }^{14}$ Meses más tarde, $E l$ Sol (Madrid, año XI, núm. 3019, 8 abr. 1917, 2) reseña la lectura de El Iluminado entre espectadores españoles y la publicación en París de un libro que reúne la conferencia impartida en la Residencia de Estudiantes y la obra Los creadores, versión traducida al español de Les Créateurs. En la misma nota se caracteriza a Osorio en los siguientes términos: "descontento de las condiciones mezquinas en que se desarrolla la vida teatral en su país, como en casi todos de la América española, acometió con suma energía una empresa: no la de buscarse un escenario en Europa que, al fin y al cabo nada tiene de inhospitalaria, sino la de convertirse en un autor francés" (2, énfasis agregado).

La puesta en escena de Les Créateurs, obra escrita originalmente en francés, dirigida por Fernand Bastide resulta ser un fracaso. ${ }^{15} \mathrm{El}$ medio teatral parisino rechaza de manera tajante la apuesta del recién llegado colombiano, las reseñas en prensa no fueron precisamente halagadoras: Jane Catulle-Mendes lo acusa de falta de experiencia escénica:

Il y a beaucoup de bonnes intentions dans ces trois actes, et le désir d'expérimenter des idées et des impressions personnelles. On y sent de la sincérité et de l'application. C'est quelque chose. Cela ne suffit pas à mettre une pièce debout. L'art, la souplesse, la mise au point, l'expérience scénique sont absents. Ces nécessaires qualités de théâtre, on les peut acquérir. Sans doute, M. Luis Enrique Osorio, dans un second œuvre, trouvera-t-il à sa pensée, une forme plus claire et mieux distribuée. (La Presse, año 92, núm. 4136, 13 jun. 1926, 2)

Del mismo tono son otras reseñas publicadas en medios como La Rampe (núm. 440, 15 30 jun. 1926), L'Humanité (núm. 10046, 13 jun.1926, 2), La Fronde (año $30 u ́ m 13$ jun. 1926, $3)$, por nombrar solo algunas.

Osorio no abandona su cometido de acumular capital simbólico y de lograr la legitimación como escritor en Francia, de hecho: su obra Madette hace parte del repertorio del teatro Athéna de Mme Régine Le Quéré en la temporada 1928-1929 (Comoedia, año 52, núm. 5751, 9 oct. 1928, 2); Le Gaulois, 5 oct. 1928, 4; L'Intransigeant, núm. 1788228, 5 oct. 1928, 7). El regreso de Osorio a Colombia en 1928 es indicio del fracaso de tal proyecto. Samper relata que Osorio trató de obtener un cargo diplomático que le permitiera continuar en Europa; no obstante, falló en su intento: "aquéllos eran los días de la hegemonía conservadora, y a Luis Enrique se le reputaba por hereje y descreído" (11). De nuevo, aparece la tensión con la clase política como un factor que obstaculiza la trayectoria del autor colombiano.

Luis Enrique Osorio regresa a Colombia en 1928, debido a las penurias económicas parisinas, se asienta en Barranquilla, de donde es oriunda Lucía Saint-Malo, su esposa. En esta ciudad caribeña retoma el proyecto de La Novela Semanal, cuya primera etapa, la eta-

Sobre la Residencia, Ribagorda (2007).

14 La Nación. Diario de la noche (año II, núm. 311, 15 oct. 1926, 7); El Año Académico y Cultural (1926); La Época (año LXXVIII, núm. 27077, 18 oct. 1926, 3).

15 En su edición del lunes 7 de junio de 1926 La Presse anuncia la presentación (año 92, núm. 4130, 2). 
pa bogotana, se desarrolló entre el 25 de enero de 1923 y el 27 de noviembre de 1924. En Barranquilla, el impreso en su segunda etapa circula entre el 24 de agosto de 1928 y el 5 de enero de 1929. Sumadas ambas etapas, La Novela Semanal alcanza aproximadamente los 200 números, agrupados en ocho series. Como en la etapa de 1923 a 1924, las características materiales de esta colección siguen de cerca el modelo argentino: papel barato, anuncios publicitarios, costo reducido y pocas páginas. El diseño de las carátulas también guarda algunas similitudes, como el uso de la fotografía del autor.

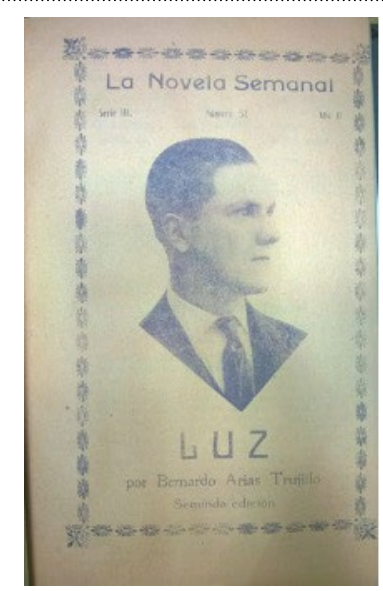

Fig. 10. Cubierta de La Novela Semanal, número 54, etapa Bogotá, 31 de enero de 1924.

Fuente: Foto Cristina Gil Medina, Colección Biblioteca Pública Piloto.

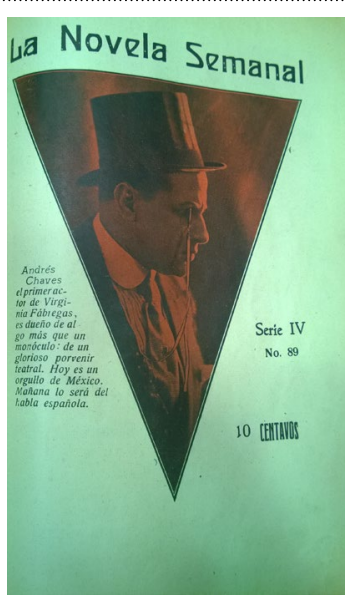

Fig. 12. Cubierta de La Novela Semanal, número 89 , etapa Bogotá, 20 de noviembre de 1924.

Fuente: Foto Cristina Gil Medina, Colección Biblioteca Pública Piloto

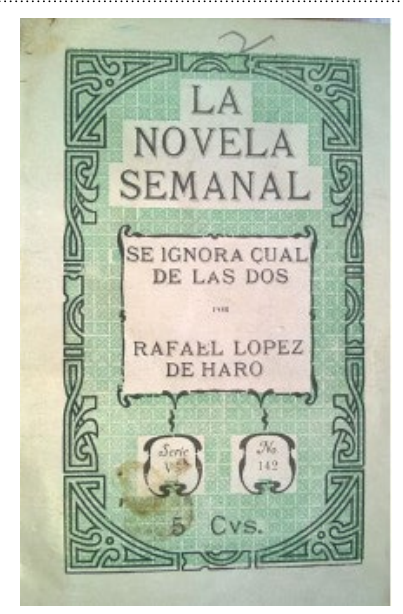

Fig. 13. Cubierta de La Novela Semanal, número 152, etapa Barranquilla, junio 15 de 1929.

Fuente: Foto Cristina Gil Medina, Colección Biblioteca Pública Piloto

En esta nueva etapa, La Novela Semanal cuenta con un equipo editorial, red de agentes en Colombia y corresponsales en el exterior. Lucía Saint-Malo, bajo el nombre de Lucía de Osorio, hace las veces de jefa de redacción, mientras que Osorio figura como director. Antonio Álvarez Lleras, el corresponsal en España, es otro de los nombres reconocidos del campo teatral colombiano del momento; Max Kahn, corresponsal en Estados Unidos, fue traductor y amigo de Osorio durante su periodo en Nueva York; con Juan José de Soiza Reilly, corresponsal en Argentina, entró en contacto durante sus años de residencia en Argentina. Gil Medina, al revisar con detalle las condiciones de la publicación, señala:

El 24 de agosto de 1928, en Barranquilla, retoma la publicación de La Novela Semanal, con algunos cambios que considera necesarios. Renuncia a la idea de publicar "novelas" exclusivamente de escritores colombianos, pues acepta la dificultad de esta intención. Sin embargo, sigue considerando la revista como una entidad de promoción y cultivo del arte nacional, a partir de la cual se busca la formación de escritores colombianos, el intercambio de ideas y su colaboración ocasional. (8) 
Además de editar La Novela Semanal, Osorio ofrece servicios de imprenta y emprende negocios en los ramos de la construcción y el comercio, gracias a los cuales recorre el país y se hace consciente de la magnitud de los problemas educativos del país (Samper). Tal revelación implica un cambio radical en su trayectoria, un viraje en su ideología que lo lleva a dedicarse a la pedagogía. Una de sus primeras estrategias en esta vía es la creación de la Legión Femenina y la transformación de La Novela Semanal en El Unionista. Órgano de la Alianza Unionista de la Gran Colombia. En una carta dirigida a Carlos E. Restrepo, ministro de Gobierno en ese entonces, le advierte: "Sin interrupción le he estado enviando la Novela Semanal, que ahora cambia su nombre por el de El Unionista, que considero más adecuado a los fines culturales que perseguimos" (Barranquilla, 4 de septiembre de 1930, Archivo Carlos E. Restrepo, Correspondencia Recibida. CER/CR/68-2 DOC. 125-185, folios 202-300, Biblioteca Carlos Gaviria Díaz, Universidad de Antioquia).

\section{Algunas conclusiones}

Pese a que fracasa en su intento de consolidar una postura autorial legitimada por la institucionalidad literaria colombiana, Luis Enrique Osorio y su apuesta editorial marcan un hito en la edición de literatura con fines de popularización en Colombia. Sus ideas a propósito de la cultura nacional, de la literatura y del teatro se ven alimentadas en sus recorridos por América y Europa; no obstante, el ambiente político de su país no favorece sus proyectos y lo lleva a buscar constantemente escenarios más propicios. En términos de Zapata, sería pertinente afirmar que la trayectoria de juventud de Osorio revela una baja "capacidad [...] para ajustar su posición y su proyecto de importación o de exportación al espacio de posibles abierto por el campo en el que se inscribe" (Zapata 7). Sus primeros tanteos en Colombia dan cuenta de un vínculo débil con la institucionalidad política y literaria. En contraste, México y Argentina ofrecen condiciones propicias, pero sus estancias en esos países son cortas debido a la ausencia de fuentes de financiación por vía diplomática que le permitan cultivar sus intereses artísticos. Esta misma razón se esconde tras su regreso de París.

No obstante, las experiencias en ambientes intelectuales foráneos no caen en saco roto. Osorio, en sus idas y vueltas por diferentes países, cumple con la función de ser vector de transferencia cultural, que tiene efectos en ciertos sectores de los campos editorial, literario, periodístico y teatral colombianos. La red de relaciones que construyó entre 1915 y 1930 alimentará futuros proyectos de corte sociológico, pedagógico y político.

\section{Referencias}

Agudelo Ochoa, Ana María y Cristina Gil. "Impresos periódicos y popularización de la literatura en Colombia (1913-1930)". De la pluma al internet. Literaturas populares latinoamericanas en movimiento (siglos XIX-XXI). Eds. Cristoph Müller y Ricarda Musser, Medellín: Editorial Eafit, 2018, pp. 181-216. http://hdl.handle.net/10784/15713 
Agudelo Ochoa, Ana María, Paula Andrea Marín Colorado y Diana Paola Guzmán Méndez, eds. La edición de cuento en Colombia en el siglo XX. Apuestas editoriales y legitimación de un género. Biblioteca latinoamericana de culturas del libro. Bogotá: Universidad del Rosario, Pontificia Universidad Javeriana, Universidad Autónoma Metropolitana, 2021.

Barrero, Ernesto Martin. El teatro de Luis Enrique Osorio. Los Ángeles: University of Southern California, 1970.

Cordero Gómez, José Ignacio. La obra literaria de Eduardo Zamacois. Tesis doctoral. Madrid: Universidad Complutense de Madrid, 2007. https://eprints.ucm.es/id/eprint/7895/1/ T30240.pdf

El Teatro, Buenos Aires, año III, núm. 63, 1922. Versión digitalizada: https://digital.iai. spk-berlin.de/viewer/index/

Espagne, Michel. "La notion de transfertculturel”. Revue Sciences/Lettres, núm. 1, (2013). https://doi.org/10.4000/rs1.219

“Evening public ledger". Chronicling America: Historic American Newspapers, (27 sep. 1922), Library of Congress. https://chroniclingamerica.loc.gov/lccn/sn83045211/1921-0927/ed-1/seq-13/

Gil Medina, Cristina. "El cuento en La Novela Semanal (1923-1930)". Revista Cultura Investigativa, vol. 8, núm. ene-jun. (2014): 1-18. https://revistaci.weebly.com/ uploads/1/5/6/0/15607460/revista_08.completa.pdf

Giraldo Gallo, Camilo Andrés. Luis Enrique Osorio: vida y obra de un periodista con visión de estadista. Trabajo de grado. Bogotá: Pontificia Universidad Javeriana, 2010. https://repository.javeriana.edu.co/bitstream/handle/10554/5559/tesis606.pdf?sequen$\mathrm{ce}=1$

Greiff, León de. Recopilación de Hjalmar de Greiff, tomo IV. Bogotá, 1923.

Gruber Garvey, Ellen. "Magazines and Fictions". A Companion to American Literature and Culture. Ed. Paul Lauter. Nueva Jersey: Wiley Blackwell, 2010, pp. 339-353.

La Novela Argentina. año 1, núm. 41, Buenos Aires, 15 agosto de 1922. Versión digitalizada: https://digital.iai.spk-berlin.de/viewer/index/

La Novela del Día, año 4, núm. 241, Buenos Aires, 25 de agosto de 1922. Versión digitalizada: https://digital.iai.spk-berlin.de/viewer/index/ 
La Novela Semanal, año IV, núm. 262, Buenos Aires, 11 de septiembre de 1922. Versión digitalizada: https://digital.iai.spk-berlin.de/viewer/index/

La Novela Semanal, número 54, etapa Bogotá, 31 de enero de 1924.

La Novela Semanal, número 89, etapa Bogotá, 20 de noviembre de 1924.

La Novela Semanal, número 152, etapa Barranquilla, junio 15 de 1929.

La Novela Universitaria, año II, núm. 42, Buenos Aires, 21 de junio de 1922. Versión digitalizada: https://digital.iai.spk-berlin.de/viewer/index/

Marín Colorado, Paula Andrea. "Las empresas editoriales de Arturo Zapata (1926-1954)". Lingüística y Literatura, vol. 38, núm. 71 (2017): 131-151. https://doi.org/10.17533/ udea.lyl.n71a07

Marín Colorado, Paula Andrea. "La colección Biblioteca Popular de Cultura Colombiana (1942-1952): ampliación del público lector y fortalecimiento del campo editorial colombianos". Información, Cultura y Sociedad, núm. 36 (2017): 65-82. https://doi. org/10.34096/ics.i36.2886

Marín Colorado, Paula Andrea. Un momento en la historia de la edición y de la lectura en Colombia (1925-1954). Germán Arciniegas y Arturo Zapata: dos editores y sus proyectos. Bogotá: Editorial Universidad del Rosario, 2017.

Martínez Arnaldos, Manuel. "El cuento semanal: proyecto y proyección”. Monteagudo, 3. a época, núm. 12 (2007): 11-26. https://dialnet.unirioja.es/descarga/articulo/2898777. pdf

Meizoz, Jérôme. Posturas literarias. Puestas en escena modernas del autor. Traducción y prefacio de Juan Zapata. Bogotá: Universidad de los Andes, 2015.

Museartes. Luis Enrique Osorio (1896-1966) Dramaturgo, director, músico y narrador. Viajero, rebelde y polemista. Exposición. https://www.museartes.net/osorio

Nagy, Denise. Novelas semanales (1917-1922) ¿Un proyecto de intervención cultural? X Jornadas Interescuelas/Departamentos de Historia. Escuela de Historia de la Facultad de Humanidades y Artes, Universidad Nacional del Rosario, Universidad Nacional del Litoral, Rosario, 2005. https://cdsa.aacademica.org/000-006/262.pdf

Osorio, Luis Enrique. Primer amor. Novela de actualidad. Bogotá: Tipografía Régulo Domínguez y Tipografía Mercantil, 1915. Versión digitalizada: https://babel.hathitrust. org/cgi/pt?id=hvd.hxfjie\&view=1 up\&seq=3\&skin=2021 
Osorio, Luis Enrique. “Odisea de un autor en busca de público”. Luis Enrique Osorio. Colarte. Patrimonio Cultural Colombiano, 1951.

Osorio, Luis Enrique. La Novela Semanal, tercera serie, núm. 53, ene. 1924, s.p.

Osorio, Luis Enrique. "Ecos de El Cuento Semanal”, El Cuento Semanal, núm. 5, 1923, 78.

Osorio, Luis Enrique. “¿Claudicación?”, El Cuento Semanal, núm. 1, 1924, segunda etapa, p. 15.

Osorio, Luis Enrique. "Por el arte propio". La Pluma Semanal, núm. 1, 1923, p. 13.

Osorio, Luis Enrique. “Concurso nacional”, Sábado, núm. 87, 1923, p. 1051.

Osorio, Luis Enrique. "Luis Enrique Osorio y el arte nacional". El Tiempo el 25 de abril de 1924, p. 9. Versión digitalizada: https://news.google.com/newspapers?nid=N2osnxbUuuUC\&dat $=19240425 \&$ printsec $=$ frontpage $\&$ hl $=$ es

Pierini, Margarita. "El programa de una empresa cultural: las novelas semanales a través de las propuestas de sus editores". Actas $1^{\circ}$ Congreso Internacional CELEHIS de Literatura. Mar del Plata, 5 al 8 de diciembre de 2001. Mar del Plata: Centro de Letras Hispanoamericanas Facultad de Humanidades (UNMDP), 2001.

Pictorial Review Spanish Versión, octubre de 1916. Versión digitalizada en Biblioteca Digital Memoria de Madrid: http://www.memoriademadrid.es/buscador.php?accion=VerFicha\&id=3129\&num_id=2\&num_total $=23$

Pineda Cupa, Miguel Ángel. “Jorge Roa y la Librería Nueva: antecedentes y aspectos esenciales sobre el editor colombiano a finales del siglo XIX". Lingüística y Literatura, vol. 38, núm. 71 (2017): 109-130. https://doi.org/10.17533/udea.lyl.n71a06

Prada Prada, Jorge. Teatro colombiano en el siglo XX. Tejido de representaciones simbólicas en la construcción de un teatro nacional. Tesis de maestría. Bogotá: Universidad Distrital Francisco José de Caldas, 2017. http://hdl.handle.net/11349/5710

Puente Pereda, Belén. Periodismo y discurso en El cuento semanal. Tesis doctoral. Barcelona: Universitat Autónoma de Barcelona, 2009. http://www.tesisenred.net/bitstream/ handle/10803/4897/bpp1de1.pdf?sequence=1

Ribagorda, Álvaro. La Residencia de Estudiantes y América Latina: caminos de ida y vuelta. Revista de Indias, vol. 67, núm. 239 (2007): 221-250. https://doi.org/10.3989/revindias.2007.i239.598 
Rojas, Daniel Emilio. Los latinoamericanos de París en el cambio de siglo. Sobre Die Hauptstadt Lateinamerikas (2013), de Jens Streckert. Colombia Internacional, núm. 87, (2016): 243-259. https://doi.org/10.7440/colombiaint87.2016.10

Samper Ortega, Daniel. “Don Luis Enrique Osorio”. El iluminado. Bogotá: Editorial Minerva, 1936.

Sánchez García, Raquel. "Diversas formas para nuevos públicos". Historia de la edición en España (1836-1936). Ed. Jesús Martínez. Madrid: Marcial Pons, 2001, pp. 241-268.

Soiza Reilly, Juan José de. "Los grandes de América. Entrevista por Luis Enrique Osorio". La Pluma Semanal, núm. 2 (9 may. 1923): 19.

Tejera, Humberto. “Osorio el joven dramaturgo colombiano". El Heraldo de México, año II, tomo II, núm. 545 (24 oct. 1920): 4.

s.a. The Pantagraph, Bloomington (Illinois), 17 dic, p. 5.

s.a. "Pictorial Review", New-York tribune (New York), April 21, 1919, p. 20.

s.a. Bulletin of The Panamerican Union, vol. LXII, ene-jun. 1921), 203.

Vasconcelos, José. El Desastre, México, Editorial Jus, 1968.

Villa, Federico. “La Novela Semanal”, Sábado, núm. 89, 1923, 1073-1074

Yankelevich Rosembaum, Pablo. "Estampas de un destierro. El periplo de José Vasconcelos por Colombia, Ecuador y Centroamérica en 1930”. Historias, núm. 56 (2007): 55-62. https://revistas.inah.gob.mx/index.php/historias/article/view/12951

Zapata, Juan. "Algunas consideraciones metodológicas sobre la teoría de las transferencias". Tradiciones de la palabra, Seminario Permanente 2016. Coords. Ana María Angulo y Paula Andrea Marín. Medellín: Universidad de Antioquia, 2016, pp. 1-9. https:// orbi.uliege.be/handle/2268/203041 